\title{
O Preconceito Linguístico no Brasil
}

\author{
Maria do Carmo Leite de Oliveira ${ }^{1}$; Theóphilo Michel Álvares Cabral Beserra ${ }^{2}$
}

\begin{abstract}
Resumo: Este artigo tem por objetivo discutir o preconceito linguístico no Brasil. Percebe-se que ainda é uma prática dominante no país, onde há uma diversidade cultural muito grande. Pretende-se ainda refletir sobre os aspectos históricos e os mitos descritos por que Bagno, me sua obra intitulada Preconceito Línguístico, tentando um paralelo com a realidade escolar. Os resultados denotam uma língua não homogênea, com domíniod de todos os nativos brasileiros e, cujas variantes culturais não dificultam a compreensão das mensagens.
\end{abstract}

Palavras- Chave: Variedades Linguísticas. Preconceito linguístico, Língua Portuguesa.

\section{Linguistic Prejudice in Brazil}

Abstract: This article aims to discuss linguistic prejudice in Brazil. It is perceived that it is still a dominant practice in the country, where there is a very great cultural diversity. It is also intended to reflect on the historical aspects and myths described by Bagno, in his work titled Language Prejudice, trying a parallel with the school reality. The results denote an inhomogeneous language, dominated by all Brazilian natives, and whose cultural variants do not make it difficult to understand the messages.

Keywords: Linguistic Varieties. Language Prejudice, Portuguese Language.

\section{Introdução}

Segundo alguns dicionários a palavra preconceito é qualquer opinião, conceito ou sentimento concebido sem exame crítico; sentimento assumido em consequência da generalização apressada de uma experiência pessoal ou imposta pelo meio, isto é, é um conceito antecipado, um "juízo" preconcebido, manifestado geralmente na forma de uma atitude discriminatória perante etnias, culturas, lugares, religiões, homossexuais, idosos, tradições etc, consideradas diferentes ou "estranhos".

\begin{abstract}
Parece haver cada vez mais, nos dias de hoje, uma forte tendência a lutar contra as mais variadas formas de preconceito, a mostrar que eles não têm nenhum fundamento racional, nenhuma justificativa, e que são apenas o resultado da ignorância, da intolerância ou da manipulação ideológica (BAGNO 2006, p.13)
\end{abstract}

\footnotetext{
${ }^{1}$ Mestranda em Educação da Anne Sullivan University. E-mail: carmem_leite63@ hotmail.com;

${ }^{2}$ Mestre em Geografia pela Universidade Federal do Ceará, Especialista em Geografia e Meio Ambiente pela Universidade Regional do Cariri, licenciado em geografia pela Universidade Regional do Cariri. Atualmente é membro do Conselho Municipal de Defesa do Meio Ambiente de Juazeiro do Norte - Ceará - COMDEMA, membro do Comitê Institucional de Avaliação do Programa de Bolsas de Iniciação Científica e Tecnológica do Instituto CENTEC. E-mail: mic.beserra@ hotmail.com.
} 
Apresenta-se aqui, uma reflexão acerca de um preconceito que ainda vigora em nossa sociedade: o preconceito linguístico. Depreciativo, desrespeitoso, humilhante, é uma situação na qual algumas pessoas, acreditam que a única forma de falar correta é aquela abordada nas gramáticas de Língua Portuguesa. Essas trazem fórmulas, normas, conceitos, classificações, prescrições, e muitas regras que devem ser seguidas, respeitadas e trabalhadas com rigor. Objetivam uma escrita acadêmica, ditas corretas, sem “erros”. Essa gramática normativa seria apenas um dos tipos possíveis, mais vinculado à escola tradicional abordada em sala de aula. Não há necessidade de menosprezo a outras formas mais populares de comunicação verbal, ou mesmo a forma falada entre pessoas que residem no campo. Estas outras formas mais populares e com menor rigor normativo, é mais simplificada e, normalmente adotada por pessoas que não tiveram oportunidade de uma escolarização adequada.

Os outros estilos de comunicação destacados nesse trabalho, representam igualmente "sinuosidades" da linguagem, isto é, com uma linguagem não-padronizada da língua portuguesa. A ideia é refletir sobre uma realidade linguística que é histórica, cultural e social, onde o falante fica mais a vontade para uma comunicação mais espontânea. É preciso reconhecer que a língua é viva e, que todos os falantes não precisam ter timidez de comunicar a sua fala, apenas porque não o faz dentro das regras fixas da Língua Portuguesa.

Do ponto de vista da história de cada indivíduo, o aprendizado da língua falada sempre precede o aprendizado da língua escrita, quando ele acontece. Basta citar os bilhões de pessoas que nascem, crescem, vivem e morrem sem jamais aprender a ler e a escrever (BAGNO 2006, p.56)

\section{Mitos Sobre o Preconceito Linguístico}

Sabe-se que a língua portuguesa falada no Brasil não apresenta "unidade", como muitos teóricos, críticos e a classe dominante brasileira acha, pois um país com mais de duzentos milhões de falantes, não necessariamente, deveria ter uma fala homogênea. Deve-se reconhecer a diversidade do português falado no Brasil, que não depende apenas de uma norma linguística ultrapassada, e transmitida ao longo de séculos, mas da idade, escolarização, origem geográfica, situação socioeconômica etc, isto é, de fatores extralinguísticos (BAGNO 2006:16) 


\begin{abstract}
No Brasil, embora a língua falada pela grande maioria da população seja o português, esse português apresenta um alto grau de diversidade e de variabilidade, não só por causa da grande extensão territorial do país, que gera diferenças regionais, bastante conhecidas e também vítimas, algumas delas, de muito preconceito, mas principalmente por causa da trágica injustiça social que faz do Brasil o segundo país com a pior distribuição de renda em todo o mundo.
\end{abstract}

Essa desigualdade social que acontece no Brasil, estimula ainda mais o preconceito linguístico, tendo a norma culta como privilegiada, o que deixa milhares de falantes, com sua própria língua materna, à margem da linguagem formal. Portanto, não se deve definir uma linguagem única para tantos estados, verdadeiros pequenos "brasis" dentro do País.

No Brasil, muitos não tem acesso a língua culta, privilegiada. Essa situação tende a manter uma espécie de separação entre aqueles que "sabem" e "podem", e aqueles que "não sabem" e "não podem". Esses últimos, aqueles que normalmente, não tiveram a oportunidade de aprenderem a utilizar correta e apropriadamente a língua dita culta.

Vale salientar que essa língua prestigiada é falada por um pequeno número de brasileiros, apenas aqueles com acesso a uma educação de qualidade. Normalmente pessoas que não tendem a uma estigmatização por não terem frequentado a escola. Seria muito desumano e descabido, marginalizar essa parcela da população, já que foi a própria sociedade que não possibilitou seu acesso a tal condição do meio social. Portanto, não é possível se falar numa língua única no nosso país, somente porque escritores e jornalistas, instituições oficiais, órgãos de poder e aqueles com a cesso a gramática normativa portuguesa, privilegiam um tipo de linguagem.

É preciso, portanto, que a escola e todas as demais instituições voltadas para a educação e a cultura abandonem esse mito de "unidade" do português no Brasil e passem a reconhecer a verdadeira diversidade linguística de nosso país para melhor planejarem suas políticas de ação junto à população amplamente marginalizada dos falantes das variedades não-padrão. (BAGNO 2006, p.18).

Outro mito bem recorrente é o que afirma que "só em Portugal se fala bem Português", brasileiro não sabe falar português". Nota-se que o funcionamento da língua falada no Brasil, é bem diferenciado da língua falada em Portugal. Inclusive algumas das expressões usadas em nosso país, somente servem neste. E quando proferidas em Portugal, parecem sem nenhum sentido. 
Tem-se muitos exemplos em relação a esse mito, grifamos o caso de colocar o pronome oblíquo átono antes de verbos, usados em Portugal nas expressões "estou a dançar", "ele está a cantar", o que jamais funcionará esse tipo de fala no Brasil.

Precisa-se observar que cada um desse países têm suas construções próprias, nenhum deles fala mais "certo" ou mais "errado", cada um tem suas peculiaridades e sua funcionalidade. O que se pode ter de "unidade" na linguagem entre essas duas nações é apenas a escrita formal, já que a ortografia é quase a mesma, mas não se pode dizer que países diferentes, só porque se utilizam de uma mesma língua, precisam falar iguais.

Segundo Bagno (2006, p.32),

Então, não há porque continuar difundindo essa ideia mais do que absurda de que "brasileiro não sabe português". O brasileiro sabe o seu português, o português do Brasil, que é a língua materna de todos os que nascem e vivem aqui, enquanto os portugueses sabem o português deles.

É pertinente destacar vários outros mitos que se apresentam para se fortalecer o preconceito linguístico em nosso país, "português é muito difícil”, "as pessoas sem instrução falam tudo errado", "o certo é falar assim porque se escreve assim”, é preciso saber gramática para falar e escrever bem", entre outros.

Quando se afirma que “português é muito difícil”, não quer dizer que é a fala que é complexa, mas a escrita tão arraigada que traz inúmeras normas que só existem na gramática tradicional, sabe-se que uma criança de apenas quatro anos já sabe se comunicar em sua língua materna com facilidade, o que a mesma não domina são as sofisticações trazidas naquele livro que todos "temem" falado bastante nesse trabalho (BAGNO 2003)

E a acusação de "falar tudo errado", atropelar a gramática ou não saber português pode ser proferida por gente de todos os espectros ideológicos, desde o conservador mais empedernido até o revolucionário mais radical (p.16).

Vale ressaltar que a língua falada é diferente da língua escrita, pode-se por exemplo escrever a palavra "menino" de uma mesma maneira em todo o Brasil, já que a escrita é uniforme, mas não se pode ter uma fala igual em um país enorme como é o nosso, já que existe 
as variedades linguísticas, o que faz com que cada cidade, estado e região fale de um modo diferente, desse modo podemos proferir "minino", "mininu", "meninu" etc.

Significa olhar para a língua dentro da realidade histórica, cultural, social em que ela se encontra, isto é, em que se encontram os seres humanos que a falam e escrevem. Significa considerar a língua como uma atividade social, como um trabalho empreendido conjuntamente pelos falantes toda vez que se põem a interagir verbalmente, seja por meio da fala, seja por meio da escrita (BAGNO 2003, p.19)

Observa-se ainda nas mídias de um modo geral, que o falar do nordestino é, quase sempre representado em novelas e seriados, de forma mais pejorativa, exposto ao ridículo. Como lembra Bagno (2003, p.21) "as pessoas sem instrução falam tudo errado". Esse mito mostra evidencia ainda mais que o preconceito, não é linguístico. Mas social. É comum a crença de que, por viverem em determinada região, no caso no Nordeste, não são capazes de dominarem a língua "culta", contribuindo ainda mais para o embasamento de haver uma língua "única", que seja a correta. No caso, aquela língua falada na escola, estudada através da gramática, livros didáticos e dicionários. Apenas esta estaria correta.

Sabe-se que pessoas que por exemplo pronunciam "Cráudia", "chicrete", "pranta", trocando a consoante "l” por " $r$ ", verbalizam assim e são estigmatizadas socialmente. Vistas como atrasadas e ignorantes, porém estudos científicos mostraram que, essa permuta de consoantes é um fenômeno fonético da própria língua culta. Muitas palavras tinham sua origem em "L" e foram transformadas em "R", como é o caso de "branco" e "prata", em que a etimologia delas eram "blank" e "plata" respectivamente. Com isso, a troca do "R" pelo "L" teria uma explicação: a consequência da formação de nossa Língua Portuguesa. Até o próprio Luís Vaz de Camões, dentro de sua valiosíssima obra "Os Lusíadas", escreveu "pubricar", "Frecha" etc (BAGNO, 107).

Pode-se notar portanto, que a maioria da população, que ainda pronuncia "pranta", "frecha", "bicicreta", todas estão inseridas no falar de uma outra variedade do português, o nãopadrão, essas não tiveram a oportunidade de estarem em uma escola, de adquirirem os conhecimentos ensinados na gramática normativa ou tradicional, como muitos a chamam. 
de falar. É inevitável que cada vez mais se aprofunde e se alargue a distância entre a língua dos portugueses e, também, entre uma norma padrão artificial e arbitrária e a língua efetivamente empregada pelos brasileiros (BAGNO, p.108)

"O certo é falar assim porque se escreve assim", outro mito que deve ser desfeito, principalmente enquanto docentes de Língua Portuguesa, observa-se muitos casos desse tipo no interior de salas de aula, na qual o aluno fala algo que não está correto de acordo com a gramática tradicional, e o professor sem respeitar as outras variedades linguísticas o corrige, fazendo aquele ser humilhado e estigmatizado diante dos colegas, fazendo com que aquela criança tenha vergonha de falar posteriormente por medo de não estar atendendo às normas gramaticais. Cabe ao professor de Língua Portuguesa a tarefa de fazer essa "desmistificação", de mostrar ao aluno que há diferenças entre a língua escrita e a língua falada, assim o mesmo perceberá por exemplo que poderá falar "bunito", "bonito" ou "bunitu”, mas na escrita só poderá escrever "bonito".

Jamais se pode falar da mesma maneira como se escreve, pois se esse fenômeno acontecer, se anularão muitas variações. Deve-se ensinar a gramática normativa com o intuito da escrita correta, já que a ortografia é oficial, mas precisa-se respeitar o modo como os diversos falantes da Língua Portuguesa brasileira o pronunciam, já que a língua é viva e não artificial. Vale lembrar que a gramática normativa é tão reverenciada porque durante muitos séculos os estudiosos gramaticais só se preocupavam em analisar a língua escrita, o estudo formal, somente no início do século XX é que a língua falada se tornou o interesse para os estudiosos, com o surgimento da Linguística como ciência.

Não se pode esquecer que antes mesmo de se obter o domínio da escrita, dos signos linguísticos, já se obtém o amplo domínio da fala, a criança ao ser inserida no ambiente escolar, já se apropria da fala, o "instrumento de sobrevivência", como lembra Bagno (2006:65) a gramática normativa oprime a língua oral, menosprezando as variedades linguísticas, e adotando a língua literária como absoluta e dominadora.

Outro mito que faz paralelo ao descrito anteriormente aborda que "é preciso saber gramática para escrever e falar bem”, o que se sabe é que esses compêndios com prescrições foram criados com o objetivo de descrever "manifestações linguísticas" adotadas por escritores de nome, admirados por uma classe privilegiada, então adotaram regras estabelecendo-as como 
"corretas", "absolutas", isto é, a gramática só surgiu porque existe a fala, e se para falar e escrever corretamente dependesse apenas desse "livro obsoleto" muitos intelectuais de livros consagrados não faziam tantas críticas a esse, o que na atualidade, graças aos estudos linguísticos estão sendo usados praticamente como um dos instrumentos para o estudo de um tipo de variedade brasileira, a padrão. E em relação aos escritores, esses que encantam multidões de leitores, se precisassem de gramática para escreverem tão bem, não seriam escritores e sim gramáticos.

Não é a gramática normativa que "estabelece" a norma culta. A norma culta simplesmente existe como tal. A tarefa de uma gramática seria, isso sim, definir, identificar e localizar os falantes cultos, coletar a língua usada por eles e descrever essa língua de forma clara, objetiva e com critérios teóricos e metodológicos coerentes (BAGNO, p. 65).

\section{Desconstruindo o Preconceito Linguístico}

Apesar de muitos acreditarem que o ensino de língua culta é o principal objeto de estudo do ensino-aprendizagem em Língua Portuguesa, como tanto aborda Bagno, tentando mostrar as outras variedades, observa-se atualmente que os professores, estudiosos e técnicos da área já não recorrem somente ao compêndio tradicional como exclusiva para a explicação dos fenômenos linguísticos. Sabe-se que em pleno século XXI os brasileiros ainda se utilizam de uma gramática contraditória, pois o que está escrito na mesma não usamos igualmente na fala, quem observa no dia a dia o falar dos milhões de brasileiros pode perceber facilmente que as pessoas não se utilizam de mesóclises, pronomes átonos antes de verbos etc, esses exemplos servem como justificação que aquela gramática não está apropriada para as diversas regiões existentes no país, totalmente diferentes, cada uma com sua cultura e seu "linguajar" próprio.

Como foi abordado no mito de língua única, sabe-se que é impossível adequar a linguagem do português de Portugal com o português brasileiro, precisa-se escrever uma gramática de Língua Portuguesa brasileira, com termos apropriados, precisos e objetivos que atendam a população de todo Brasil, sem distinção, discriminação. Mas, como se sabe que essa gramática ainda estar aquém de nossas expectativas, falantes brasileiros, precisa-se combater o 
preconceito linguístico com os "recursos" que dispomos, primeiramente aceitar que todo usuário nativo de uma língua tem competência comunicativa, sabe se utilizar da língua. Os professores de Língua Portuguesa devem mostrar e discutir em sala de aula que não existe "erro" de português, mas diferenças entre a língua falada e língua escrita, a língua privilegiada e língua falada pela maior parte dos brasileiros (BAGNO 2003, p.164)

É preciso abandonar tais pruridos e escancarar o português brasileiro: dizer que as regras do nosso vernáculo são certas e válidas, de modo claro e explícito, e não com observações em letra pequena ou em notas de rodapé.

Precisa-se aceitar que toda língua evolui com o tempo, varia e vai se transformando, o que consideramos como "certo" hoje, futuramente pode ser analisada como "erro", como bem analisou Bagno a palavra "ele", escrita assim no século XXI, no século XIX se escrevia "elle", até metade do século XX "êle". Ressalta-se portanto, que a variedade linguística deve ser respeitada, pois a língua é identidade de um povo.

Enfim, com toda competência linguística que os usuários de língua materna têm, em termos de língua pode-se proferir "tudo", porém no contexto adequado, pode se usar gírias, palavrões, chavões, linguagem técnica, linguagem bem elaborada, rebuscada, simples etc, mas, mantendo um equilíbrio entre a adequabilidade e a aceitabilidade, isto é, falar como "achar melhor”, já que se tem muitas probabilidades de fala, o que vai depender é quem é o interlocutor e qual o objetivo da retórica proferida.

\section{Considerações Finais}

Ao longo do presente trabalho tentou-se refletir sobre o preconceito linguístico existente na Língua Portuguesa brasileira. Questionou-se alguns mitos que ainda torna-se alvo de muita discriminação e separação entre aqueles que "sabem" e os que não "sabem". Também se procurou desconstruir esses mitos, de forma a conscientizar que, todo falante tem competência comunicativa para falar o português brasileiro. 
Cabe às escolas, como grande formadora de opinião, principalmente aos docentes da área de linguagens mostrar que a língua não é homogênea, trabalhando com os discentes não apenas o tipo de gramática estabelecida por lei, mas a linguagem coloquial, a não-padrão, assim o próprio discente entenderá e saberá criticar os diferentes tipos de variedades linguísticas existentes, sabendo quando e qual delas servirá no contexto o qual pretende proferir. (CEREJA e MAGALHÃES 2008, p.10),

\begin{abstract}
Neste momento de transição, não é necessário abandonar tudo o que os professores e alunos historicamente vem aprendendo de gramática. As terminologias tradicionalmente apresentadas pela gramática normativa, por exemplo, podem até ser aproveitadas (evidentemente, não sem críticas ou revisão), mas sempre como meio, e nunca como fim.
\end{abstract}

Vale lembrar que a escola não deve ensinar a como falar, já que a criança ao entrar naquele espaço educacional já domina a gramática internalizada de sua língua, mas deve mostrar a enorme variedade de usos da fala, para que o discente possa entender a fala de sua comunidade, de sua família, de seus antecedentes, a fim de que o mesmo entenda a evolução linguística, as diferentes variedades e não passe a ser mais um preconceituoso enquanto estudante de Língua Portuguesa, por achar que fala "correto" e os outros "errado".

\title{
Referências
}

BAGNO, Marcos. A Língua de Eulália: Novela Sociolinguística.15ª ed. São Paulo: Contexto, 2006.

BAGNO, Marcos. A norma oculta: língua e poder na sociedade brasileira. São Paulo: Parábola Editorial. 2003.

BAGNO, Marcos. Preconceito linguístico: o que é, como se faz. $47^{\mathrm{a}}$ ed. São Paulo: Loyola, 2006.

CEREJA, William Roberto e MAGALHÃES, Thereza Cochar. Gramática, texto, reflexão e uso. $3^{\text {a }}$ ed. Reform. São Paulo: Atual, 2008.

HOLANDA,Aurélio B. Minidicionário de língua Portuguesa. $4^{\mathrm{a}}$ ed. Revista e ampliada do minidicionário Aurélio. 7ª impressão - Rio de Janeiro, 2002. 
HOUAISS, Antônio. Dicionário Houaiss de Língua Portuguesa. Rio de Janeiro, Ed. Objetiva, 2001.

Como citar este artigo (Formato ABNT):

OLIVEIRA, M.C.L.; BESERRA, T.M.A.C. O Preconceito Linguístico no Brasil. Id on Line Revista Multidisciplinar e de Psicologia, Nov-Dez. de 2016, vol.10, n.32, p. 179-188. ISSN: 1981-1179.

Recebido: 17/09/2016

Aceito: 22/09/2016 